\title{
Obsessive Compulsive Disorder and Eating Disorder: Is there a link?
}

\author{
Pragya Lodha \\ Clinical Psychologist, Desousa Foundation and Minds Foundation, Mumbai \\ Corresponding author: Pragya Lodha \\ Email - pragya6lodha@gmail.com
}

\begin{abstract}
Obsessive Compulsive Disorder is seen to have links with eating disorders which have been demonstrated in the early 1900s and is supported by the personality trait of 'compulsion neurosis'. Personality traits shown to be shared between EDs and OCD are perfectionism and neuroticism. The review further explores overlapping factors between the two conditions.
\end{abstract}

Keywords: Mythology, psychology, ego development, cognitive development.

(Paper received $-30^{\text {th }}$ January 2019, Peer review completed $-2^{\text {nd }}$ April 2019)

(Accepted $-8^{\text {th }}$ April 2019)

\section{INTRODUCTION}

Obsessive Compulsive Disorder (abbreviated as OCD) is defined by the Diagnostic and Statistical Manual $5^{\text {th }}$ Edition (DSM-5), as "recurrent and persistent thoughts, urges, or images that are experienced as intrusive and unwanted" [1]. Understood alternatively, it is a disorder in which a person experiences repeated thoughts, feelings, sensations, behaviours, or ideas (obsessions) that lead them to the engagement of a ritual or repeated habit (compulsion). OCD is a sub-type of anxiety disorder.

Obsessive compulsive disorder is depicted by feelings of apprehension or uneasiness, and the use of repetitive behaviours is aimed at reducing the correlated anxiety. Individuals with OCD attempt to ignore or suppress these thoughts, urges, or images or to neutralize them with some other thought or action by performing a compulsion. These repetitive obsessions are not under the conscious control of an individual and cause marked distress to them.

Obsessive Compulsive Disorder, more often, is seen as a comorbid condition, with illnesses such as substance abuse or eating disorders.

Symptoms of OCD include [1] -

Obsessive thoughts

- Common obsessive thoughts in obsessive-compulsive disorder (OCD) include:

- Fear of being contaminated by germs or dirt or contaminating others.

- Fear of causing harm to yourself or others.

- Intrusive sexually explicit or violent thoughts and images.

- Excessive focus on religious or moral ideas.

- Fear of losing or not having things you might need.

- Order and symmetry: the idea that everything must line up "just right."

- Superstitions; excessive attention to something considered lucky or unlucky. 
Compulsive behaviours

- Common compulsive behaviours in obsessive-compulsive disorder (OCD) include:

- Excessive double-checking of things, such as locks, appliances, and switches.

- Repeatedly checking in on loved ones to make sure they're safe.

- Counting, tapping, repeating certain words, or doing other senseless things to reduce anxiety.

- Spending a lot of time washing or cleaning.

- Ordering or arranging things "just so."

- Praying excessively or engaging in rituals triggered by religious fear.

- Accumulating "junk" such as old newspapers or empty food containers.

Eating Disorders (ED) are described as illnesses that are characterized by irregular eating habits and severe distress or concern about body weight or shape. Eating disturbances may include inadequate or excessive food intake which can ultimately damage an individual's well-being. The most common forms of eating disorders seen in prevalence are Anorexia Nervosa, Bulimia Nervosa, and Binge Eating Disorder. Relatively, females are affected more than males.

Obsessive compulsive disorder is often directly connected with eating disorders [2]. Behaviours that are obsessive-compulsive can be frequently seen in eating disorders, such as anorexia, bulimia, and binge eating disorder. Conversely, several behaviours or rituals that are characteristic of eating disorders can be and rather, are considered compulsive, especially as they are often performed in an attempt to reduce the anxiety / discomfort / distress experienced. Obsessive thoughts related to eating that could lead to compulsive behaviours include thoughts related to weight, eating, food, or body image. There is a constant chain of thoughts in the mind of the individuals that persuade them to keep a check on the calorie count, exercise (more than required) and feeling that they are not in shape. Compulsive behaviours often observed with eating disorder behaviours include:

- Excessive exercise (more than required)

- Constant checking or examining appearance in mirrors

- Counting caloric intake

- Frequently weighing self

- Use of diuretics or laxatives to reduce weight

- Following particular "rules" or "rituals" when eating a meal

- Rigidly tracking intake of carbohydrates, sugars, fats and other nutrients/ micronutrients

\section{How are OCD and ED similar}

Often times, eating disorders are characterized by behaviours similar to that seen in OCD, such as obsessive thoughts about food and calories, food rituals such as cutting food symmetrically, or hoarding of food items. For an individual who is struggling with a comorbid condition of eating disorder and obsessive-compulsive disorder, foods are chosen based on colour, weight, shape and other factors; and often the two conditions are linked through the attempt to obtain perfectionism.

Many individuals who suffer from an eating disorder may also experience a struggle with Obsessive Compulsive Disorder (OCD). Research demonstrates a statistical finding of nearly two-thirds of people suffering from eating to have been previously diagnosed with another form of anxiety disorder and of that, $41 \%$ of eating disorder sufferers have had obsessive compulsive disorder [3].

Salbach-Andrea et al. (2008) examined comorbidity of psychiatric diagnoses in adolescent girls with anorexia and found $73.3 \%$ of the girls had a comorbid diagnosis, including mood disorders $(60.4 \%)$, anxiety disorders (including OCD) (25.7\%), and substance use disorders (7.9\%) [4]. Furthermore, another recent study showed that $65 \%$ of those with an eating disorder also met criteria for an anxiety disorder. Amongst these individuals, anxiety disorders preceded the development of the eating disorder in $69 \%$.

A commonality between ED and OCD is the manner in which the levels of anxiety are reduced, that is through carrying out ritualistic behaviours. The cycles involved with obsessive-compulsive disorder and eating disorders are vicious, repetitive, and can easily begin to overlap with one another. Eating Disorders can evolve as an inherent progression of OCD. More specifically, individuals who suffer from 
anorexia commonly diet and exercise excessively; those with bulimia usually develop a vicious cycle of binging and purging. In both instances, extreme and often life-threatening behaviours that consist of either consuming too little or too much food typically stem from intrusive obsessive thoughts

For example, an individual with OCD might perform a ritual by chewing their food for a pre-meditated number of times that is "just right" before ingesting. Similarly, a person with anorexia may count bites or pieces of food eaten in a sitting as a means of restricting or limiting portions. In both these cases, rituals are developed to reduce the anxiety caused by a triggering obsession, such as fear of eating or weight gain. Yaryura-Tobias and Neziroglu proposed that eating disorders may be considered part of the OCD spectrum but since then the boundaries among anorexia, nervosa, bulimia nervosa, and OCD remain blurred [5]. Thus, the challenge for clinicians becomes recognizing whether the condition is a particular form of OCD, or actually an entirely separate but related disorder with symptoms that merely have an obsessive-compulsive quality to them. In debate, most people do not think of eating disorders as being part of the spectrum of OCD, and the relationship between the two disorders has gone relatively unstudied. When patients seek help from mental health professionals in order to alleviate their suffering, clinicians may often mistake ED for OCD or the vice versa as resultant from the overlapping presentation of the two conditions.

However, researchers have been speculating the parallels between OCD and eating disorders since 1939 [6]. Numerous studies have now shown that those with eating disorders have statistically higher rates of OCD $(11 \%-69 \%)$, and vice versa $(10 \%-17 \%)$. Theoretically and seen through research findings, it is more likely for a person with ED to have OCD than the vice versa. The unidimensional link of ED to $\mathrm{OCD}$ is stronger than the reverse.

\section{Why do OCD and ED co-occur}

The link between eating disorders (EDs) and obsessive-compulsive disorder (OCD) dates back 6 decades, as far as 1939. It was first supported by the observation of common personality traits such as "compulsion neurosis" [7] and "compulsive obsessive". Recent research says that personality traits of perfectionism [8,9] and neuroticism [10-12]. have consistently been identified that are found to be common between EDs and OCD. The existence of shared personality between OCD and ED is thus a reason for cooccurrence. Research in retrospect [13-16] indicates that individuals with comorbid ED and OCD develop the ED at a younger age and experience a more chronic, unremitting course of illness compared to individuals without a comorbid OCD diagnosis.

\section{How can Obsessive Compulsive Disorder be differentiated from Eating Disorders}

Understanding the mechanisms that underlie the co-occurrence between these disorders contributes to a better understanding of clinical course, common etiology, and aid in the development of new treatments designed to target shared underlying mechanisms of dysfunction. To differentiate between the two disorders and arrive at a proper diagnosis, it is crucial for the clinician to more closely examine the specific behaviours that are being observed and the motivations behind those behaviours. Whereas patients with eating disorders are primarily driven by concerns of physical appearance, and consequently alter their eating patterns in order to lose weight accordingly. OCD patients may be restricting their eating for reasons very different than body image concerns. Furthermore, for cases in which an individual qualifies for both diagnoses, such as an anorexic or bulimic who also experiences non-food related OCD symptoms, like checking or contamination, it is still imperative to consider whether or not their symptoms are being motivated by both disorders simultaneously. Recommended psychological treatment for both OCD and eating disorders involves some combination of cognitive-behavioural therapy, antidepressant medication, and family counselling. For treating eating disorder, additional techniques involve gradual alteration of eating rituals and increased flexibility in eating behaviours which may include breaking rituals such as the need to use the same utensils to measure food, to time meals, and to avoid certain restaurants. This helps reduce the viscosity of the obsessive and compulsive elements in the ED [17]. 


\section{REFERENCES}

1. American Psychiatric Association. Diagnostic and statistical manual of mental disorders (5th Ed). Washington, D.C. American Psychiatric Association; 2013.

2. Cederlof M, Thorton L, Baker J, Lichtenstein P, Larsson H, Ruck C, Bulik C, Mataix-Cols D. Etiological overlap between obsessive-compulsive disorder and anorexia nervosa: a longitudinal cohort, multigenerational family and twin study. World Psychiatry 2015;14(3):333-8.

3. Kaye WH, Bulik CM, Thornton L, Barbarich N, Masters K, Price Foundation Collaborative Group. Comorbidity of anxiety disorders with anorexia and bulimia nervosa. Am J Psychiatry 2004;161(12):221521.

4. Salbach-Andrae H, Lenz K, Simmendinger N, Klinkowski N, Lehmkuhl U, Pfeiffer E. Psychiatric comorbidities among female adolescents with anorexia nervosa. Child Psych Hum Dev 2008;39(3):261-72.

5. Yaryura-Tobias JA, Pinto A, Neziroglu F. The integration of primary anorexia nervosa and obsessivecompulsive disorder. Eating Weight Disord 2001;6(4):174-80.

6. Altman SE, Shankman SA. What is the association between obsessive-compulsive disorder and eating disorders ?. Clin Psychol Rev 2009;29(7):638-46.

7. Palmer HD. Anorexia nervosa as a manifestation of compulsive neurosis. Arch Neurol Psychiatry 1939;41:856-60.

8. Bardone-Cone AM, Wonderlich SA, Frost RO, Bulik CM, Mitchell JE, Uppala S, Simonich H. Perfectionism and eating disorders: current status and future directions. Clin Psychol Rev 2007;27(3):384405.

9. Bulik CM, Tozzi F, Anderson C, Mazzeo SE, Aggen S, Sullivan PF. The relation between eating disorders and components of perfectionism. Am J Psychiatry 2003;160(2):366-8.

10. Cassin SE, Ranson KM. Personality and eating disorders: a decade in review. Clin Psychol Rev 2005;25(7):895-916.

11. Lilenfeld LR. Personality and temperament. Curr Top Behav Neurosci 2011;6:3-16.

12. Samuels J, Nestadt G, Bienvenu OJ, Costa PT, Riddle MA, Liang KY, Cullen BA. Personality disorders and normal personality dimensions in obsessive-compulsive disorder. Br J Psychiatry 2000;177:457-62.

13. Carter JC, Blackmore E, Sutandar-Pinnock K, Woodside DB. Relapse in anorexia nervosa: a survival analysis. Psychol Med 2004;34(4):671-9.

14. Lo Sauro C, Castellini G, Lelli L, Faravelli C, Ricca V. Psychopathological and clinical features of remitted anorexia nervosa patients: a six-year follow-up study. Eur Eating Disord Rev; 2012

15. Milos G, Spindler A, Ruggiero G, Klaghofer R, Schnyder U. Comorbidity of obsessive-compulsive disorders and duration of eating disorders. Int J Eating Disord 2002;31(3):284-9.

16. Steinhausen HC. The outcome of anorexia nervosa in the 20th century. Am J Psychiatry 2002;159(8):128493.

17. Pollack LO, Forbush KT. Why do eating disorders and obsessive-compulsive disorder co-occur?. Eating Behav 2013;14(2):211-5.

$* * * * * * * * * * * * * * * * * * * * * * * * * * * * *$

Acknowledgements - Nil

Source of Funding - Nil

Conflict of Interest - Nil 